Review Essay

\title{
A MuSiCAL PICTURE Of INDONESIA
}

\section{Jan Mrázek}

Music of Indonesia, recorded, compiled, and annotated by Philip Yampolsky (Smithsonian Folkways and the Indonesian Society for the Performing Arts, 19911999), 20 vols. [Titles of individual volumes and more discographical information follow the essay.]

I have chosen to write about this twenty-volume series as a whole. Each volume is significant in its own way, and a reviewer of a single volume might do better justice to the particular volume. However, the series does very much form a whole, and it is the appearance of the series as a whole-rather than the release of any single volumethat is an event of such significance, it should make us pause and listen.

Size does matter, but large spaces can be used well or wasted. Philip Yampolsky, the editor, is to be applauded for being able to realize the full potential of the space given to him and to build in the space a monumental work. He made the scope of the series-the number of well-represented kinds of music from various regions of Indonesia-one of its most impressive features. It is against the background of the size and scope that one should admire the quality and quantity of scholarly work that has gone into the project, the ambitious overall concept, a certain unifying consistency of vision (or hearing, or philosophy, or emotion) behind the overall plan and behind each selection, the care with which every item has been selected and presented-each selection (and each volume for that matter) has a clear raison d'être in the larger whole-, the power and inner life in each piece of music, and the fact that the series, as a whole, makes a powerful statement.

One way to approach the series is to consider it as a monumental musical picture of Indonesia. As such, the series is not only immensely important for people interested in Indonesian music, but it also makes a great contribution to our understanding of the country.

I have spoken of a consistency of vision. But this vision does not flatten the musical landscape. On the contrary, what the overall picture shows, more than anything else, is a variety and diversity of (musical) creatures. Yampolsky writes that the series "offers a sampling of this tremendous variety." (All vols., p. 1) People often 
speak of the diversity in Indonesia; but the series succeeds in doing something more than mere reporting. As one listens to the different kinds of music, one gets an intensely physical experience of the diversity. One does not merely hear about it; one hears it. One hears how people move their bodies and breathe differently and in different meters and rhythms; one hears different voices; one hears how people shape and use material things to create particular kinds of sounds and musical structures; and, in the variety of musical structures, one perceives different ways of organizing sounds and social relationships (for collective music-making is always also that). In the music, one hears people's histories and ways of being. One could say that one gets a preconceptual experience of the diversity, yet at the same time this is part of the musical concept of the series, and it is the act of bringing the different kinds of music together that allows one to hear the variety.

I need to say more about what kind of diversity the series shows. Let me make a comparison. I am thinking of a cassette, a copy of which I got from a friend, produced in Indonesia and called Songs from Whole Indonesia (Lagu-lagu dari seluruh Indonesia). It offers, it seems to me, the New Order government's vision of Indonesia, represented by music. Rarely does one encounter this vision in such a pure form, distanced from and uncomplicated by the reality of what happens in Indonesia. The tape contains one loooooong composition. It is an uninterrupted medley of songs from all the provinces of Indonesia. What is most striking, if I can use that word, is that the whole time, for the songs from all the twenty-seven provinces, there is only one beat, one tempo, one way of singing, one musical idiom (a kind of castrated march music), one kind of feeling. The tape is thus a musical equivalent of New Order projects such as "Taman Mini 'Indonesia Indah"" ("The 'Beautiful Indonesia'-in-Miniature Park), or of certain shows on television in which, for instance, the dances from all the provinces are performed on a single stage in the same, clean, tidy, and glamorous manner. Diversity, on the tape, as in Taman Mini, is a major theme. But it is diversity tamed by a vapid unity, diversity represented only to show that things are ultimately all the same, without tensions, songs from everywhere sung all to a single beat in a single tempo, lacking a distinct character and inner life.

State's representations of Indonesia and its arts and traditions have been analyzed in scholarly literature about Indonesia, an important task because these representations are an important force in Indonesia. However, the focus on the state's representation and state's politics has led to under-representation of what happens beyond the limits of the state's control and the life, tensions, play, that persist despite it or, somehow, "beneath" or apart from governmental politics, the life and play that can be found when governmental politics change tone as they penetrate into everyday life. More recently, a number of scholars have pointed out that this trend in scholarship, by focusing on the politics of the state's representation of Indonesia and by adopting (even while criticizing) its terms (which were often adapted from colonial ethnography in the first place), reinforces the state's picture because it, too, fails to represent what is happening beyond, beneath, and in the gaps of, the state's representation. ${ }^{1}$

${ }^{1}$ For further discussion, see essays by Tony Day, René Lysloff, Andrew Weintraub, Matthew Cohen, and my Introduction, in Puppet Theater in Contemporary Indonesia: New Approaches to Performance Events, ed. 
Yampolsky's work focuses on showing the persistent vitality and diversity of traditional music. "Traditional" for Yampolsky means music whose "scales, idioms, and repertoires do not in any obvious way derive from European/American or Middle Eastern (or other foreign) music." 2 Yampolsky's definition of "traditional" is based on the particularity of a music and its local ties, on music's belongingness to a particular community, rather than on a respect for antiquity or purity, and he emphasizes that all the recorded music is part of people's lives in present-day Indonesia. The larger significance of his focus on traditional music can be grasped, for example, from the following statement from the recording notes to one of the volumes focusing on Sumatra:

The importance of the music heard in this album-and throughout the Music of Indonesia series-lies not so much in its possible antiquity or "purity" as in its current vitality and independence (not to mention the purely musical interest). These musics, energetically performed and obviously full of meaning for the musicians, borrow little or nothing from European and American music, or Middle Eastern music, or Javanese gamelan music. They don't even sound like music from elsewhere in Sumatra. Their context and frame of reference are wholly local; they spring from and are directed to their own communities. Such affirmation of the immediate community in the age of global media would deserve respect and admiration even if the music itself were less compelling than it is. (vol. 4.)

Throughout the series, one feels respect for the specificity of each kind of music, each way of being, and each place, and for the continuing vitality of these local ways.

Yampolsky's picture of Indonesia is thus radically different from that of the Indonesian all-in-one-beat tape discussed above, and from the pictures painted by the New Order government and scholarship that focuses on the cultural politics of Indonesian government. In sharp contrast, this picture shows not how the state would like Indonesia to be seen, but rather what is happening in different places in Indonesia, despite or regardless of the state. It wonderfully reflects the heterogeneity of Indonesia, a discontinuity in what is Indonesia, indeed a lack of the very unity and homogeneity that the government has tried to impose. It is a picture so rich that it is unnerving. If I were the Indonesian president, I would ban this series. One feels from the music, one experiences physically, how Indonesia is unconstrained, full of energy, full of stark differences among its people. This is one of the things that the series lets be heard.

This feeling is strongest when one looks at the picture as a whole. On the other hand, if one listens to individual compositions, one gets more often the feeling of life and energy at peace with itself. It would seem, as one listens to the music, that people feel more at home where they are, in a particular locale, than they do when seriously reflecting on and attempting to represent the diversity in Indonesia, the (im)possible wholeness of Indonesia. At the present moment, as I listen to the different kinds of music and its "tremendous diversity," I find it difficult not to think about the separatist movements in different parts of Indonesia and all the violence, and also

Jan Mrázek (Ann Arbor: Center for South and Southeast Asian Studies, The University of Michigan, forthcoming in 2001).

${ }^{2}$ Quoted from the general introduction found in all volumes. 
190 Jan Mrázek

about the lack of genuine communication and community-forming across Indonesia. It is not that the diversity itself would have to lead to this; it may be more due to the state's cover-up of this diversity, its attempts to suppress it, and its failure to treat it with respect for what it is.

There is this uneasy passage in the notes for the last album of the series:

[C]an peoples who are historically enemies, or who today are rivals for land or power or rights or food, enjoy each other's music (or respect each other's culture)? Can people of one religion enjoy the music of others whose beliefs they reject? Can music that grows out of a vanishing way of life still be respected and enjoyed by those who now live in a different way? The belief implicit throughout the series is that these questions can be answered yes.

At some moments, as I think about some cases, I tend to agree with this statement. Certainly many people respect and enjoy "music that grows out of a vanishing way of life," whether this is a sign that old ways of being are more persistent that they appear (this is often the case), whether it is precisely because the old ways of life are vanishing or left behind in the village and people who have moved feel they need at least something of the old ways, or whether it is because music is able to detach itself from its origins and be significant for people in a new situation. At other moments-such as when I think about the probability of people from one part of Indonesia enjoying the traditional music of another-I cannot help but be reminded of the ending of $A$ Passage to India by E. M. Forster: "Not here, not now."

The selection of recordings in Music of Indonesia shows somewhat less attention to the tensions and conflicts between traditional music and forces that try to flatten the musical landscape, to turn this earth of mankind into a supermarket or a theme park. Here the series faces a major problem: one of its goals is to present something of the fascinating music of Indonesia-and it succeeds impressively-but this makes its picture of Indonesia somewhat biased, because it under-represents all the music that is not pleasant to hear, precisely because that kind of music reflects Indonesia's problems, maladies, idiocies, weaknesses, cultural vapidity, or it manifests the leveling of the musical and cultural landscape, Indonesian and global-one thinks of "trivialized" (Yampolsky's word) traditional music and some commercial pop music, or perhaps the "Songs from the whole Indonesia" tape. All the music in the series is full of inner energy, and one feels that it is made by human beings for whom one can feel only respect and admiration. This makes a wonderful sound recording, but it creates a musical picture of Indonesia that is potentially misleading. This does not mean, in the least, that the impression one takes from the series is untrue, for there certainly is a tremendous musical vitality and richness in present-day Indonesia. Only, one needs to understand that the series tries to show certain aspects that were not visible before or that were under-represented in previous pictures of Indonesia, rather than to offer an objective "registration" of all the music one hears in Indonesia.

The series is not indifferent to the various Indonesian difficulties, ailments, and conflicts: they are behind the argument that the musical recordings make about the vitality of Indonesian music, and on occasions they are explicitly discussed in the commentary. One feels the problems and conflicts from the notes to the volumes and from the fact that at least some of this music-precisely the music that is shown to be 
full of inner life-is in Indonesia marginalized or trivialized. Incidentally, anybody interested in some of the thinking that shaped the series-for in the recording notes themselves, much is only implicit-should read Yampolsky's essay, "Forces for Change in the Regional Performing Arts of Indonesia."3

Nonetheless-while I fully appreciate the decision to give priority to traditional music in the series and surely do not argue against it (as I hope this essay as a whole shows)-in the future, I might be interested in exploring in greater depth also those kinds of music that have emerged recently and that bring traditional music closer to commercial pop music, or indeed transform traditional music into commercially successful music; music that is in the gray area between the traditional and the nontraditional ("traditional" as understood in the series), or that challenges that distinction. I am thinking about such genres as the recently extremely popular Javanese campursari (which appears in many guises, from music that is close to gamelan sensibility to music in which dangdut or disco or "house music" beats are dominant), but comparable genres, in many cases stimulated and/or formed by the interests of the recording industry, exist and are popular in other parts of Indonesia as well. On the one hand, these genres can be seen as examples of trivialization and commercialization of traditional music, and generally of the process in which traditional music in its richness is pushed aside. On the other hand, they manifest something of the musical and cultural atmosphere and life in present-day Indonesia, and demonstrate how traditional music is transformed and recontextualized. The music in itself reflects the conflicts and compromises between the traditional and the modern, or shows that sometimes it is not so clear on which side one is. Moreover, even musical (or generally artistic) idiom that is devoid of life is often penetrated by a new vitality, and this breath of life may be stimulated in part precisely by its inner conflicts, dilemmas, difficulties. This can make the music say something about Indonesia and the liveliness and energy can make for good listening. 4

Foreign pop music, as well as pop Indonesia (one of the many forms of Indonesian pop music, and one of the most popular), are quite prominent in the Indonesian soundscape and in the music market, but they are not represented on the CDs. The absence is not surprising, but it is another sign that this is not an "objective" picture that would disinterestedly register everything, but, rather, the picture focuses on certain phenomena and leaves out others. This is another way to say that behind the picture there is a perceiving human being, and that the series responds to, contributes to, and often critiques an existing body of knowledge and existing pictures of Indonesian music.

\footnotetext{
3 Philip Yampolsky, "Forces for Change in the Regional Performing Arts of Indonesia," Bijdragen tot de Taal-, Land- en Volkenkunde 151,4 (1995): 700-25

${ }^{4}$ It may be that these genres are not explored in depth in part because of the editor's decision and the philosophy behind the series, but, to be fair, it should be noted that part of the reason could be the fact that new commercial modern-traditional genres have perhaps become more visible in the musical scene after the series was planned in the early 1990s (certainly this is true about campursari). As I discuss later in the essay, older hybrid genres, which are often close to traditional music, are well represented in the series. In any case, what I have said suggests a direction for further musical picturing of Indonesia, and it also reminds us that the Indonesian musical landscape continues to change.
} 
If one is used to thinking about music in Indonesia as primarily pop music and some classical gamelan, Yampolsky's contra-representation reveals the complexity of the musical landscape. On the other hand, an uninitiated listener (especially a Westerner), particularly one who does not read the commentaries carefully, might not perceive one aspect of the complexity of and tensions in the Indonesian musical landscape, which stem from the presence of the different kinds of foreign pop music and their coexistence and interaction with more Indonesian kinds of music. It is left up to the listener to put the two together: on the one hand, we have music that is (globally and/or in Indonesia) easily accessible, well-known, and dominant, but not represented in the series (though its presence is acknowledged in the notes); and, on the other hand, we have all the other music that is often unknown beyond the area where it is performed, but important to people in that area, and that is represented in the series. However, the inclusion of hybrid genres and certain kinds of Indonesian pop music (those that are not predominantly Western in idiom, but that contain elements of Western music) points the listener to this complexity.

For the focus on local, traditional music is only one aspect of the picture. The series shows also that there is some communication-not only violence-going on between the diverse parts of the country. There does exist a kind of mixing and coming together that is different, and perhaps more pervasive, than that which one sees in the picture painted by the state; the series shows this process very well. The cassette with a medley of songs mentioned above, representative as it is of an important force, does not represent a major popular genre, even though the songs themselves are part of the musical indoctrination of Indonesian school children, and, as one such indoctrinated ex-child put it, the songs "remain in your body." Taman Mini is mostly deserted, except for lively events that contradict it and themselves, such as some performances that Taman Mini fails to tame even within its own walls. What is popular and alivein addition to musically Western pop music and traditional musics-are various kinds of music that incorporate elements from different kinds of music. These form a significant part of the picture Yampolsky paints, and the decision to include a variety of these genres, indeed give them a significant place in the picture, makes the series only more valuable and the picture richer and truer ... and also more complex, for this makes for another kind of amazing variety. As one listens to the different forms of music that reflect and manifest cultural interaction, one realizes that communication and human encounters do not lead only to homogenization. The variety of these genres is no less striking than the variety of those kinds of music that have existed at one place for a long time. In the series, the "hybrid" genres are not presented separately from others, and this was a good decision, not only because the designation of "hybridity" is often a matter of perspective (Javanese court gamelan and its culture can certainly be called hybrid), ${ }^{5}$ but also because in the real world these genres coexist, interact, and indeed have originated from the interaction of genres that may (or may not) be less obviously "hybrid." The musical picture gives one the feeling that if Indonesia is more diverse than unified, there is lively, uncontrolled interaction within and without Indonesia.

5 See, for example, Sumarsam, Gamelan: Cultural Interaction and Musical Development in Central Java (Chicago: The University of Chicago Press, 1995). 
It is interesting that the most pan-Indonesian genres, such as forms of pop music, are also most indebted to and resemble music from outside Indonesia. It seems that Indonesia, when it comes closest to unity, avoids its own riches and, with it, its own diversity, or draws on them only with hesitation, preferring to look outside Indonesia. It is as if the foreign that one can imitate or differentiate oneself from was the most important thing that people across Indonesia had in common; or as if, even musically, the life and variety of locally popular music was too threatening to the state of "being Indonesian." 6 On the one hand, the more traditional, local genres-and there is a continuity rather than clear separation between local and national-are rarely appreciated by more than one ethnic group; to reach beyond that, typically the musicians incorporate musical elements from outside Indonesia. As Yampolsky writes, "institutions (government, established religion) and commercial media ignore traditional music when aiming at national audiences." (vol. 20, p. 26) On the other hand, many of the traditional genres popular locally reflect traffic between different places and musical cultures, as well as continuities across large regions of Indonesia (though never across all of Indonesia) and often beyond (for example, the Malay cultural area that Yampolsky discusses in the notes to volume 11 covers parts of Indonesia and Malaysia). There are also important musical continuities related to religion (such as music associated with Islam or the Christian church), and/or contact with more distant cultures (European, Chinese, Arab, etc.). Yampolsky shows their importance by, inter alia, recording particular kinds of music in places where one might not expect to find them: Moslem music in Maluku, Christian church songs and Western-influenced music in the Irian province, and so forth.

Being an art historian, I find it difficult not to think about other kinds of art. Indonesian textiles, for example, manifest the same kind of "tremendous variety," the connections and interaction across different parts of Indonesia, and the incorporation of non-Indonesian elements (Indian, Chinese, Arab, European) evidenced in this collection of music; looking at textiles, one sees the various ways in which foreign influences (such as particular patterns) were adapted to create uniquely local works, and often the same motif (such as those found on the Indian patola cloth) inspired strikingly different textiles in different parts of Indonesia. One could think further here about the relationship of music to other kinds of arts, and especially about the potential benefit of studying them together. So far, unfortunately, due to the divides between academic disciplines, interdisciplinary studies of this sort have rarely been undertaken. And yet, in much of my work on Indonesia, I have found it useful and often necessary to go beyond the distinction between the different arts and not be limited either to the visual arts or music (or even the performing arts, generally). Considering that in Southeast Asia, art works and architecture, music and performing (and verbal) arts, generally, are often elements of a single artistic structure, a single event, a single experience; considering that, in many Indonesian cultures, they are structurally or aesthetically related or hardly separate; and considering that their histories, geographies, and social functions greatly overlap and often coincide-all things considered, I believe that the study of the visual arts should try, whenever fruitful, to learn from and speak to the study of music and performing arts in Southeast Asia, and, conversely, (ethno)musicological work would profit from a

${ }^{6} \mathrm{Cf}$. Yampolsky, "Forces for Change." See also notes to Music of Indonesia, volume 20, . 
194 Jan Mrázek

greater attention to non-musical elements of events of which music is one element, and would profit generally from attention to related visual arts. The picture of Indonesia is much richer if one considers both the visual and the performing arts, and the way that the two are often one. Literature or verbal art in Southeast Asia is also closely linked to other arts, and often the same stories or myths are represented verbally, visually, and in performance-either separately, or (as in theater) in the same event. The same stories come to life in different media, on different occasions, and in different cultures, and in each case what the story is, and what it does, is somewhat different. Continuing this line of thought, I would argue that this series is relevant not only for people interested in music, and that it could be used in classes on Indonesian art(s), generally, rather than only in courses on (ethno)musicology. Secondly, I am suggesting that the series presents a challenge to, for example, art historians (if I may talk to myself), not only to show a comparably rich picture of Indonesia through their presentation of material arts, but also to relate their picture to Yampolsky's musical picture, indeed to show in a single picture how the different arts coexist and are often inseparably linked. Who knows--perhaps in the future the Ford Foundation, which has funded the series, will pay an art historian to create such a picture.

Geography is one important consideration guiding the organization of the series, a decision which results in an emphasis on both the belongingness of each kind of music to a place, and on regional diversity. While in some cases a volume focuses on an indepth presentation of a single genre as it is performed at one place, in many other cases the series shows the variety of music within one region, making the picture richer yet. However, musical geography is not the only factor shaping this collection, for one encounters many other themes and questions that have clearly influenced the organization of the series and the choices that have been made. These other themes cut in various ways across the regional divisions, both on individual CDs and in the series as a whole. For example, the editor will compare various versions of a particular kind of music that can be heard in different parts of a region (for instance, volume thirteen compares string music from five different parts of Kalimantan), or in different parts of Indonesia (volume fourteen focuses on gamelan for wayang on Java, Lombok, and Kalimantan, and the last volume focuses on a single instrument, the guitar, as it is played in very different ways in various parts of Indonesia). The series' last volume also beautifully exemplifies another major theme of the series, the creative adaptation of non-Indonesian elements. In some cases, the guitar plays with Western musical conventions, while in other cases the idiom is entirely different.

I have said that the series forms a whole. If the last volume, as Yampolsky notes, constitutes a kind of summary of the whole series and focuses especially on manifesting the variety across Indonesia and the musical interaction with outside musical cultures, the first volume can be seen as an introduction that emphasizes the point from which the series starts: the continuing life-energy in traditional music. In contrast to the last volume (and to other volumes), this first album is devoted to a single performance, "[in] order to allow the listener to enter into the aesthetic of the genre and feel the music's sweep and breadth."(vol. 1) In the commentary, the editor makes his point in another way, by describing a dance party that he attended which was not a success: most of the people left or were getting drunk and showed no interest in the dance and music. After a break, the musicians and the dancer performed the suite on which the album focuses, and which traditionally concludes the event. 
"For over an hour they performed, with strength and energy that I believe they drew mainly from the seriousness of their intent: to reaffirm the art of gandrung in the face of the drinkers' assault, to use the order and restraint of its music and dance to restore the order that had been disturbed." This story foreshadows what the whole series contemplates: the power of art in the face of all sorts of assaults on it.

Each volume has a central theme or a central question and contributes something new to the whole of the series, but there is also much cross-referencing across the series, and often one CD explicitly complements another. For instance, the string music of Kalimantan on volume thirteen is complemented by volume seventeen, which also focuses on Kalimantan-but on music other than strings-as well as by volume fourteen, on which one can hear Kalimantan reinterpretations of Javanese gamelan. Moreover, one is led to compare this complex picture of Kalimantan to the picture of Sulawesi; as was true for Kalimantan, Sulawesi has one $\mathrm{CD}$ dedicated to strings from different regions, and another to other kinds of music. And, being overwhelmed by the richness and variety of string music on these two islands (and there are many examples of string music on other volumes), one finds on volume twenty a variety of ways of making music using guitar across Indonesia. Similarly, other themes are pursued on different volumes across the series, and the recording notes alert the listener to attend to these connections. For example, the variety of gong ensembles in different parts of Indonesia is equally impressive as the variety of strings, and for anybody familiar with Javanese and Balinese gamelan, it is heart-tickling to hear what all can be done with gongs.

It is by combining geographical and what could be called thematic organization that the series is able to articulate the patterns that I have discussed above, such as the combination of "tremendous variety," the connections across the different parts of Indonesia, and the existence of comparable musical phenomena in different parts of the country. But ultimately, the main consideration that guides the organization of the series is musical, for it is in music that the different themes and local and ethnic ties are manifested, and even geography, as treated in the series, is a matter of music. As we will see later, for the editor the musical and the conceptual are often hardly separate.

Volume two focuses on three important forms of pop music (rather than trying to offer a complete survey), but there are also pop songs scattered in many of the other volumes. Both in the volume dedicated to pop music and in other volumes, the choices and presentations of the songs are clearly motivated by particular questions about pop music, which are also the questions that energize the series as a whole and connect pop music into the overall picture and show it in a particular context. These are principally questions about the tensions between the tremendous diversity of regional music, on the one hand, and the centralized character of pop music. While pop music in Indonesia is, to various degrees, like Western pop music, and one of the most popular genres (not recorded by Yampolsky), pop Indonesia, is "almost entirely Western in musical idiom" (vol. 2), Yampolsky records those genres that are uniquely Indonesian, if only in the way they combine various foreign musical elements. On volume two, after focusing on the Indonesian character of pop music in Indonesia, he goes on to show how these forms of national pop music produced at the power center of Indonesia and "aimed at Indonesians without regard to their ethnic and regional affiliations" are in the "regions" adapted to local tastes and musical conventions, and often transformed 
in character. On other volumes, pop songs appear in the contexts of particular regional and thematic foci and are often performed in a regional musical idiom. Thus, even in the presentation of pop music, Yampolsky emphasizes regional ties and variety.

The next volume, three, elaborates on the presentation of pop music in volume two by focusing on the place most associated with national and international pop musicJakarta. Yampolsky starts painting the picture of Jakarta by describing the dominant, "visible" image of Jakarta:

The visible Jakarta is the capital city, the center of the Indonesian government and the national television and radio networks, and also the center of the film, recording, and magazine publishing industries. Practically all information and entertainment that is addressed to Indonesia as a whole emanates from Jakarta, and a great deal of it is also about Jakarta-about government officials in Jakarta, about the glamorous singers and actors in Jakarta, their clothes and their automobiles and their easy commerce with the big city and the modern world. The imagery of Jakarta is increasingly the only imagery common to all Indonesians: the nation's idea of itself is an idea of Jakarta. For the entertainment industry in particular, the rest of the country is made up of "regions," and what happens in the regions is of no interest, aside from touristic curiosity, to anyone who does not live there or come from there. (For example, the only cassettes of music by Indonesians that are distributed nationally are certain studio-polished genres of urban popular music, recorded almost without exception in Jakarta; cassettes of "regional" music are marketed only in their home regions and to emigrants who have maintained their regional ties.) Jakarta is thus the opposite of the regions: they are the disparate parts of the nation, Jakarta the unified whole. (vol. 3; emphasis in the original.) ${ }^{7}$

After this excellent description of the dominant imagery of "the visible Jakarta" and its unique significance in Indonesia, Yampolsky focuses on "a Jakarta that is virtually invisible, one that most people have forgotten exists" (and it is curious that even the extreme poverty in Jakarta, more easily visible than its culture, is not central to the average Indonesian image of the city-perhaps because Jakartan poverty is not unique in Indonesia and certainly not desirable and pleasing and fantasy-stimulating, whereas the glamour is). The album says: even in Jakarta, the very center from which the cultural uniformity is disseminated through powerful, sexy, glamorous, wealthobsessed, cosmetic images of the fetish of (national, global) modernity, the very same modernity that frames traditional music and local ways of being as backwards, undeveloped, as a matter of the past with no future, as the ways of people who have no power, no money, no future-even in Jakarta, there are local people with their own history, culture, music, sense of self, who are not visible in the common Indonesian images of the city, and who are "virtually invisible" (is this an allusion to "virtual reality"?). The album shows this by presenting gambang kromong, "paradoxically [...] the regional music of Jakarta," which integrates Chinese, European, and American (jazz) musical idioms and instruments, interlaced with domestic strains of music, for "[u]nderneath of this runs what is essentially a Sundanese (West Javanese) percussion

7 The notes for this volume were written by Yampolsky and Danilyn Rutherford. 
group, with intricate and tonally-varied drumming straining against and then resolving into an unvarying cycle of gong-punctuation."

Its performers and audiences are ordinary people, and the Jakarta they live in is no more sophisticated or cosmopolitan than other cities and towns elsewhere in Indonesia. Unlike the audience for national popular music genres, gambang kromong's audience can be defined quite specifically in ethnic, economic, and geographic terms. And, as it happens, the music itself reflects with unusual clarity the development of its audience. While the popular music produced in Jakarta's studios embodies the ideal of a uniform culture throughout the country, gambang kromong expresses one region's cultural history in all its particularity. (vol. 3)

Incidentally, the picture of Jakarta presented in volumes two and three is further complemented by volume five, which presents music from Jakarta and its environs with special focus on the "Betawi-Sundanese connection," while volume three, discussed above, "considers a different nexus of musical interaction-among 'Chinese,' Betawi, and Europeans/Euroasians" (vol. 5), even though obviously the foci of the two volumes (or three, including volume two) overlap. ${ }^{8}$

This enlarged, multiform picture of Jakarta is only one example of the way in which the series often reveals what is "invisible" in stereotypical images of Indonesia as a whole (such as Taman Mini) and of specific places. Another example, in some ways opposite to the album focusing on Jakarta, can be found in volume ten, which presents music from the province Irian Jaya. The stereotypical image of this easternmost part of Indonesia is one of primitive peoples with little or no contact with the outside world. Here too Yampolsky shows that generalizations misrepresent a more complex reality. The album focuses on a particular island and ethnic group, (the) Biak:

With their long history of contact with outsiders, Biaks belie the stereotype of New Guinea as a land untouched by time. Their culture bears witness to the lasting effects of a colonial frontier and the ongoing importance to Biaks of sup ambèr, "the land of the foreigners." As the music on this album should amply demonstrate, this society has shaped itself by imaginative engagement with external powers from the west and the West. (vol. 10, p. 3.)

The album presents, on the one hand, a variety of vocal music showing no Western influence, and, on the other hand, church hymns sung by a female choir and stringband dance music that combine Western idioms with the aesthetics of vocal music presented first. "By bringing the three genres together, we hope to suggest the energy of Biak's culture past and present, and the richness of Biak's artistic strategies for incorporating and domesticating the foreign, the surprising, and the new." (Ibid.)

The stereotypical Jakarta is modern, glamorous, Westernized-but Yampolsky presents the local music of common people that reflects the long history and identity of the region. The stereotypical Irian is primitive, untouched by time and outside

8 The three volumes overlap not only because they all concern music from the Jakarta area, but, musically, the brass-band-like tanjidor ensemble, for example, can be heard on all three albums: in volume two, it plays a dangdut song, in volume three a song commonly played by gambang kromong, and volume five focuses more specifically on the ensemble (as well as two others). 
198 Jan Mrázek

influences-but Yampolsky presents music that reflects the people's creative engagement with other cultures and with the new.

Yampolsky's revelation of the "invisible" does not stop at proving prevalent or authoritative representations of Indonesian culture to be "slightly" imperfect and/or misleading; at times, this series, as shaped by the editor, ridicules them and strongly opposes their view of the world. The music itself acts as evidence to challenge their validity and authority. In his volume on Maluku, after a brief discussion of how the people whose music he recorded call themselves, Yampolsky writes. "From the government's point of view, reflected in the Statistics Bureau's maps and lists of villages [...], it hardly matters what they call themselves, since there are no people there at all: the large interior region that includes Lake Rana (itself not shown) is all 'forest,' a blank on the map, with no recognized settlements." (vol. 19, p. 16.) Yampolsky does not simply say that there are people invisible in the government's apparently objective representations; he lets us hear many kinds of their music. He lets us hear that there are not simply people to count for statistics and maps, but also people to be felt and listened to, for we can feel the richness and intensity of their lives and their connection to the place where they live from their music, so that at last one begins to feel the human significance of the lake invisible in the government's maps, but central to the poetic texts of the songs and in the stories behind the musical compositions. An example of such story: "A man went out on the lake in a boat and began to row, heading somewhere, but it was so calm and lovely on the water, with no wind, that he came home instead and made this piece." (vol. 19, p. 20.)

I have already mentioned that music that is (almost) purely Western in idiom is not represented in Yampolsky's picture. Also not heard are those kinds of music best known to people outside Indonesia: Balinese and Javanese gamelan, specifically the well-known forms of it. Yampolsky writes about his decision:

We must say most emphatically that the reason for this is not that we do not regard these great arts as worthy of inclusion. Balinese music and Central Javanese gamelan music are extraordinarily rich arts, and any complete discussion of "the music of Indonesia" must consider them at length. But our series does not hope-cannot hope, in twenty volumes-to be complete. There are many fine recordings of Balinese and Central Javanese music available in Indonesia and abroad. Our aim is to bring other sorts of Indonesian music to people's attention, to stand beside those that have already achieved recognition. (vol. 14., pp. 3-4; emphasis in the original.)

This is a good reason. And yet, however "most emphatically" this may be said, it seems to me that there is a more complex thinking behind the decision not to include the obvious. This decision is a part of a larger plan, which is implicit rather than explicit in the commentary. By leaving gamelan out, and showing everything other than it, Yampolsky makes, "quietly" but powerfully, a statement. He contradicts the most basic outline of the conventional picture of Indonesian musical landscape, and presents a strikingly different, alternative picture. But this picture does not contradict only Westerners' conventional vision; it also contradicts a politically dominant 
Indonesian vision of Indonesian arts. In other words, by not including the best-known and politically dominant forms of music in a rich twenty-volume series of Indonesian music, Yampolsky once again calls attention to the vigorous diversity of Indonesia. And if the plenitude of gamelan recordings is inseparable from the fortunate and unfortunate association of this kind of music with political power, Yampolsky's series is politically in opposition. "Our aim is to bring other sorts of Indonesian music to people's attention, to stand beside those that have already achieved recognition." (his emphasis) Recognition is an important word here: the recognition that Yampolsky speaks about is both a question of making people perceive (recognize) more than they have perceived before-opening their eyes and ears-and a question of political recognition-letting what has been made invisible by the dominant forces and representations show itself.

Incidentally, Yampolsky's decision to exclude Balinese and Javanese gamelan is closely related to his decision to exclude Western pop music, discussed above. The absence of Western pop music, too, is a sign that the series tries to show that which has been hidden in its variety and vitality. This does not mean uncovering forms of "traditional" music that belong to the past, but, more importantly, moving close enough to the ground, to particular places where music is made, paying attention to local creations rather than only to what is nationally or globally profitable. I should add that the two significant absences in the series are not just vaguely similar, for these two kinds of music-pop and classic gamelan-represent two power centers. The "visible Jakarta," with the glamorous commercial entertainment industry, on the one hand, and the Central Javanese "Principalities," with their court culture, on the other, musically represented by Western-style Indonesian pop music and Central Javanese gamelan, respectively, are the two most visible and most powerful features of Indonesian politico-cultural landscape, and they are closely interconnected-one could even see them as two faces of the same power.

In their conspicuous absence, the well-known forms of gamelan are perhaps more noticeable than if they were included. In some ways, Yampolsky's argument starts from gamelan: it is "the Javanese and Balinese orchestras generally called gamelan" that are the first kind of music mentioned in the general introduction that accompanies all the CDs, and it is against the backdrop of their renown that Yampolsky says, in a latter part of the same sentence, "but gamelan is only one aspect (albeit an impressive one) of the whole." Follows a discussion of what the series is about: the diversity that exists beyond the best-known and the most powerful. In some ways, then, gamelan is the starting point.

The series offers both a pointer beyond gamelan and a picture of the diverse musical landscape that includes well-known gamelan music as one feature. The latter is done both by presenting music from other "families" than gamelan-strings, solo or choral vocal music, etc.- and by including a variety of gong ensembles from different parts of Indonesia, for gong ensembles make up the larger "family" to which gamelan belongs. Yampolsky's selections illuminate how many of the gong ensembles are musically very different from the well-known forms of gamelan. Of course, among (ethno)musicologists, Yampolsky is not alone in his interest in going beyond the wellknown forms of gamelan, but never before has the variety of music other than gamelan been presented in such an forceful, comprehensive, and monumental manner. 
The series also shows the failure of total political and capitalist domination of the arts. It justifies one's feeling that not only outside, but also in gamelan, there is musical vitality not unaffected, but persisting, despite efforts to control it. Recent studies of wayang, a performance form closely associated with gamelan and politically dominant like gamelan, have shown that these performing arts, at the same time that they have been used by many different governments to their own ends, have not been tamed and themselves continue to contradict, reinterpret, or just ignore dominant visions, even those of their sponsors, in part by retaining their character as performing arts (personal experiences, communal events) never fully explicable in terms of politics only. ${ }^{9}$ These studies are, in some ways, parallel to Yampolsky's effort and support the statement that Yampolsky has made with his series.

The one volume of the series focusing on gamelan also makes this point. The volume (number 14) is entitled "Lombok, Kalimantan, Banyumas: Little-known Forms of Gamelan and Wayang," and it presents kinds of gamelan that are musically rich, yet strikingly different from the well-known forms of gamelan (the ensemble ajeng from West Java, recorded on volume five, is another fascinating little-known form of gamelan). This music thus opposes the narrow view that conflates Indonesian music with the well-known forms of gamelan, not by contesting the musical value of those ensembles, but by opening our eyes to the diversity and vitality of gamelan music. The gamelan jemblung of Banyumas, in which the instrumental parts are sung by a few performers using standard vocables, is not only a joyfully local reinterpretation and a low-cost version of Central Javanese court gamelan that shows a degree of admiration of that music, but jemblung is at the same time a laughing-loving parody of both the refined court ensembles and itself. It seems to me that this genre illustrates the editor's contradictory feeling towards the well-known forms of gamelan.

This quiet opposition or resistance inherent in regional music is verbally articulated in a statement that is, it seems to me, in some ways a fundamental credo of the series, but which Yampolsky has made elsewhere:

[E]ven if co-opted, the regional arts, to the extent that they employ techniques, idioms, and materials not found in the arts of the dominant culture, remain inherently oppositional. Not in a directly political sense, but conceptually: they declare that there are alternative ways to organize perception and experience. No matter how much the presentation and interpretation of, say, Central Javanese gamelan music have been altered to fit official purposes, its elements-the intervals in its scales, the structures of its composition-are stubbornly independent. ${ }^{10}$

"Not in a directly political sense, but conceptually"-or I am tempted to say musically. But it turns out that in this case the conceptual and the musical stand together. And this is an important point about the series: the concepts behind it, the ideas of the editor, are primarily musical, as are his most important means of expression. It should be obvious from what $I$ have said that this does not mean that the series is interesting only for musicologists or only for people interested in music. It is rather that

${ }^{9}$ See the essays by Andrew Weintraub, Mathew Cohen, Tony Day, and René Lysloff, and my Introduction, in Puppet Theater in Contemporary Indonesia, forthcoming in 2001.

10 Yampolsky, "Forces for Change," p. 722. 
Yampolsky lets music show, in its own way, people and the world, and he does not reduce music to the object of ethnography or another discipline. For Yampolsky, it is the very sounds and structures of music-"ways to organize perception and experience" - that are "inherently oppositional" and "stubbornly independent." The picture of Indonesia that the series presents is truly musical, and from this derives its novelty, truth, and power.

Yampolsky says that he is a musicologist, not an ethnomusicologist. While the ethnic and regional ties of music are important in the concept of the series, the series surpasses ethnography by treating ethnicity as one aspect of a musical creature or one force in the musical landscape. In other words, music presents a complex picture of which ethnicity is only one feature. When I listen to, say, Stravinsky, I am aware that he is a Russian and I hear his music against the horizon of what I know of Russian music and about Russian culture and history, but my experience of the music cannot be reduced to my knowledge about the composer's ethnicity, and the music cannot be fully explained by saying that it is Russian (apart from the fact that Stravinsky might have composed it while in France or Switzerland). Yampolsky makes me listen to Indonesian music as I might listen to Stravinsky-not as something exotic, but primarily as fascinating music. This does not mean that music is free from its ties to a place and time. These ties make the music, qua music, yet more complex and fascinating. One is made to enjoy the music, one is invited to discover it as one might discover a composer. This is a sign of respect for the music-there is no attempt to make the music appealing as simply "ethnic" or "exotic." As an ethnic myself, I find this focus on music as music rather than its ethnic-ness very refreshing.

Moreover, daring to call this music and treating this as music-rather than as an ethnographic item-is an act that opens up what is music and expands our category of music, just as the work of an avant-garde composer might do. Hence comes the possible initial difficulty (in some cases more than others) of appreciating this music at first hearing. The commentary can help greatly in teaching one to appreciate the music that is new to one's ears and whose richness may reside elsewhere than where one is accustomed to find it, but one needs to approach it with a willingness to learn, rather than with the arrogance of a prejudiced mind. Approaching Indonesian music as music does not mean simply applying Western musical theory to Indonesian music, which would often lead to misunderstanding the principles of the music. Yampolsky's notes start from listening to music, and his constant and primary concern is to understand, to hear with understanding, what is happening in the music, that is, to hear people's "ways to organize perception and experience." For this purpose, Western musicological terms and categories are used when helpful, but they are freely amended, and sometimes explicitly criticized as unsatisfactory. It is the combination of listening to Indonesian music as music - that is, as something comparable to what we call music-and uncompromising attention to the particular musical sounds and structures-that is, an attention to how this is not only like, but also different from, what we non-Indonesians and even many Indonesians know as music-that allows the series to speak to the larger question of what is music. Precisely because it takes the difference seriously, this attitude is daring and actively expands what is known about music as a human phenomenon. Having spoken about the challenge that the series poses to the students of other kinds of arts, such as visual arts, I might add here that the study of visual arts needs to do the same thing with art that Yampolsky does with 
music: to let the study of Indonesian art speak to our understanding of the human phenomenon of art, to expand our picture of what is art, rather than to reduce the study of art to ethnography.

As one's view of music is expanded by the music in the series, one finds that the Western image of music-in the nitty-gritty details of the working of music-and musicological categories turn out to be "provincial." Yampolsky's discovery and discussion of "irregular" meters in different parts of Indonesia is an example. While much Western music is in twos, threes, or fours, and more complex meters are quite unusual (except in some modern music that consciously tries to differ from the standard), in different parts of Indonesia Yampolsky has recorded music in five, seven, or fourteen, as well as "shifting meters," such as repeating groups of $10+8+6+6$, or a piece that starts out with $8+8+7+5$ and later shifts to $9+9+7+4$. Yampolsky comments-and in the comment one can see how the series makes one reconsider basic musicological assumptions about what is music-"Western musicology has no satisfactory term for them: instead it provincially describes any music not organized in twos, threes, or fours (or certain multiples of these, namely six and twelve) as having irregular meter." (vol. 17, p. 9; emphasis mine.)

From thinking about music generally, let us come back to the picture of specifically Indonesian music, using the same example. Yampolsky writes: "Even more than polyphonic singing, the presence of triple and 'irregular' meters in Indonesian music has escaped attention." (vol. 17, p. 9) The presentation of ways of making music that have previously "escaped attention" not only expands this picture, but one can again feel that the editor criticizes and repaints the conventional picture, rather than just adding to it. The following passage-conclusion to Yampolsky's discussion of "irregular" meters on volume 17-shows how Yampolsky's attention to the structural aspects of music ("technical matters") is able to go against conventional images of Indonesian music and replace them with a picture characterized by respect for (even special attention to) what is "other" and different, for the particularity of each way of being, and especially for those ways of organizing perception and experience that are not dominant or that are not considered standard.

We have dealt with this technical matter at length because it seems important to present evidence against simple generalizations about Indonesian music. While it is true that fours are ubiquitous, it is also true, as we demonstrate here, that very different practices exist as well. And it is not that the other meters are found only in archaic cultures unacquainted with the joys of quadruplicity: the same people heard playing in five or seven on one track play in four on others; and even the metric chaos of senggayung ${ }^{11}$ is balanced in the Jelai by the four-square music of the gong ensemble (tracks 2-4). (vol. 17, p. 10)

Having written about the absence of the well-known Javanese and Balinese gamelan ensembles on the series, I should add that in the discussion of irregular meters, too, one can sense that fighting "simple generalizations about Indonesian music" concerning the

11 Senggayung: music played on bamboo tubes, which are left broken in the forest after the ritual period during which the music is played. According to Yampolsky, this music is "characterized by constantly shifting and predominantly "irregular' meters," the pieces being "memorized, with no room for improvisation and no need for reliance on a leader's signals." Music of Indonesia, notes, volume 17, p. 15. 
dominant fours is closely related to the way that the series argues that there is more to Indonesian music than gamelan. This is apparent from the very first sentence of the discussion of "irregular" meters: "Especially if one comes in by way of gamelan, it is easy to think that the basic metric unit of Indonesian music is four." (vol. 17, p. 8) Then, a brief description of the squareness of gamelan (beats grouped into 4, 8, 16, 32, $64,128,256,512)$ leads into the discussion of the other, less well-known ways of ordering music and playing with time: "But there are other meters in Indonesia." (vol. 17, p. 9) The structure of this argument is reminiscent of the general introduction to the series, where, as I have pointed out above, an initial mention of the fame of the gamelan is followed by "but gamelan is only one aspect [...] of the whole" and a discussion of the variety of Indonesian music.

By saying that at the center of Yampolsky's attention are musical sounds and structures, I do not want to give the wrong impression that Yampolsky ignores or is not interested in the context, history, and geography of music. The recording notes provide excellent accounts of these, and in many cases they offer concise studies of various cultural and historical issues. Perhaps even more importantly, one can hear in the recordings (and Yampolsky's notes help one to hear it) that music itself is a form of human behavior, a way to organize perception and experience, that making music involves particular (and exciting) ways of shaping and moving human bodies, controlled work with breath, social interaction with other people (other performers, audiences, etc.), and that the very sounds and structures of music manifest people's way of being in the world, their place in space and in history, and their affinity to other people, whether these happen to be the people standing next to them or those whom they do not even know, but who make music-organize perception and experience-in a similar way.

It is in this light that one has to see Yampolsky's passion for hearing and understanding, and letting other people hear with understanding, what happens in music itself (I will discuss the limits of audio recording and the focus on music shortly). As a musicologist, Yampolsky does not let the logos dominate music. The recording notes always lead back to the sounds of music. It is through speaking about music, often about its inner workings - the relationship between voices, the meter-that the text speaks to larger issues. The text confronts one with the sounds and helps one to perceive them, rather than explaining them away. The organization of the series itself, as I have pointed out, and thus the organization of the recording notes, is primarily musical-" "what we are producing here is sound recordings, not ethnographic monographs." (vol. 13, p. 8, and elsewhere) This is a powerful and a new way to "picture" Indonesia. A picture is worth a thousands words, and the same could be said about this musical picture. This is not to underestimate the power of words, and a picture or music does not really say more than a single word, but it always says or does something a little different than a word or a thousand words can do.

It is a pleasure to see how Yampolsky is able to show the significances of the different musical structures and differences between them and speak about them with emotion, rather like a poet is able to show the poetic significance or force of phenomena that other people might consider boringly common. A person with such a skill, who writes about the arts, is able to bridge the distance between our meaning of 
"technique" (as in "it's just a matter of technique") and the original meaning of technikós.

One thing that the focus on musical structures fails to give its true significance, it seems to me, is something like what Barthes called the "grain of the voice," even though I am thinking about both vocal and instrumental music. It is something not entirely separate from musical structure, but it is not (fully) analyzable in terms of meters, tuning, and such aspects of musical structure that musicology is able to isolate. It may be, in part, affected or influenced by them, but it is not reducible to any one of them. Even if (and I don't think this is the case) the grain of the voice and the unanalyzed total feeling of a piece of music were the total effects of the different musicological categories (meter, tuning, etc.), this does not mean that the analysis of all the categories would tell us everything about the grain of the voice and the total feeling and force of a piece of music. Think about a structurally trivial song given a breath of life by a singer's emotion and personality: this is something that the passion for musical structures fails to address. And even in structurally complex music, complexity of structure is not necessarily everything. The individuality and the energy of each kind of music in the series are (especially for a non-musicologist) in some ways more immediately perceptible from the different feeling of the "grain of the voice" than from an appreciation for the different musical structures, but they are also more difficult to analyze and categorize in a scholarly paradigm. Perhaps one does not need to write about them. After all, this is, first of all, a set of "musical recordings, not ethnographic monographs," and in this respect, more than in any other, the music is able to speak for itself. The commentaries are not limited to the discussion of musical structures, and they look at music from many perspectives, and statements about the force, energy, and vitality of the music, as well as the particular emotion of a piece of music, refer the listener to listening to the music. In any case, the "grain of voice" -the total feeling of each piece-is certainly one of the most immediately impressive and appealing aspects of the music on the series.

That musical recordings are central to the series does not mean that the commentary is not important. Precisely because the music is new and unfamiliar to most listeners, because the series focuses on the little-known or previously unknown, the commentaries are essential. Perhaps the commentaries are comparable to captions in a picture book, where the captions can show the interest of a picture, point to particular characteristics or details, and help the viewer to understand the larger context of what is visible in the picture.

In addition to the attention to the inner working of music, the commentaries combine encyclopedic surveys relevant to understanding the context of the music with lively, often unforgettable, stories and histories-stories and histories of the people who make or listen to the music, as well as observations and experiences of Yampolsky and his team, which often tell much about Indonesia and give an impression of what is happening in Indonesia. The commentaries are full of the phrase "we were told"-comments, explanations, theories of local musicians, listeners, sponsors, observers, or connoisseurs of the music-and generally there is a great emphasis on the musician's and the local people's own perspectives and understanding of their music. Descriptions of the events at which music is played-not idealized contexts, but actual occasions-further enliven the commentaries. 
The commentaries, like the music, picture first of all present-day Indonesia, and they render the present historical moment, but they also give a sense that each kind of music has a history, and the histories are often discussed at length. Often, older and newer styles, contexts, and functions of music are compared, and the commentaries show how histories of particular communities are reflected in the histories of their music.

The writer of the notes is also obviously attracted to aspects, patterns, and qualities of the music for which there is no (satisfactory) explanation, to the puzzling, to that which we do not yet understand-he often focuses on this rather than trying to hide it. He often presents puzzling facts that give one a feeling of the limits of what is known so far. ("To all of these pieces that do not fit, we will add a few more and then give up on the puzzle." vol. 19, p. 14) This interest in emphasizing that there is much that is not known about Indonesia, that the picture is, to some extent, a puzzle, has to be seen as another manifestation of the tendency of the series to focus on the "invisible," the "little-known," the "other," and Yampolsky's intense effort to open up people's perception to what is invisible in generalized, stereotypical, oversimplified images, and to the limits of representations of Indonesia that pretend to show everything.

In order to understand the musical picture, we need to think about the technology, hidden as it is behind the recordings. The technology makes the series possible not simply in the sense that it allows one to record music, but also in its further effects: it allows the editor to lift the music from its context, to bring samples of the different kinds of music together to compose a new picture, and finally, to make possible a new experience of the music. It is not a small thing to be able to listen to voices from Irian or Flores while drinking cold beer and eating potato chips or freshly made bread with Gouda cheese and watch the snow softly falling outside. I can't help it, this is a great pleasure made possible by the technology, and Yampolsky's interest in music itself, and his choice of music that is good to listen to, encourages, in my case at least, this kind of enjoyable listening. This kind of pleasure is different from the pleasure of attending live performance-events, but it is surprising how much-this is my feelingdoes "get through." The medium may not be the whole message, but it is indivisible from the perception of content.

But I do have mixed feeling about the medium of clean digital audio recording, which is inseparable from the musicological attitude of the series. The digital recording lets one clearly hear all the musical sounds and structures that the series is aboutusually much more clearly than one would in real life, for "non-musical sounds" are generally suppressed on a recording. I do appreciate the value of such recording. Listening to it is a unique experience, and the series itself shows best the fruitfulness and the advantages of such an approach. It may be also close to the way a musician listens to music, though in many cases a good musician, as he performs, has to watch carefully dance or puppet movements, or has to adjust or respond to other things that happen at the event of which the music is a part. Specifically in Indonesia, music is often only one element in a performance that involves other elements, such as dance 
and/or theater, and the performance itself is more often than not only one element of a larger event or a larger experience, such as a communal celebration or simply a social gathering. In the same way that an art object-say, a wayang puppet-placed in a museum vitrine can be seen "better" than in reality-from close up and with a focus undisturbed (or unenriched) by the totality of sensations with which one is presented at a wayang performance-so the digitally recorded music can be, and has to be, listened to with a different kind of attention than most people would use at a live event. Like in the case of the art object in a museum, the recording technology separates musical sounds from everything else, from all the "noises" and all other sensations, from the larger whole of which musical sounds are usually a part, from the unique moment of which it is a part. The recording notes provide information about the context of the music, but however well they do it, they serve primarily as "background information"; they tell us what we do not hear and see. The lively photographs also help: if one looks, for example, at the picture of the dancers and colorful textiles on the cover of volume seventeen, or the smiles on the faces of the professional female partydancer and the woman with whom she is dancing, late at night, on the cover of volume one, or the clown-contortionist, his legs up in the air playing a string instrument behind his back on the cover of volume fifteen, one gets a strong impression that much more is happening than music making. The musical sounds themselves-assisted by the background information-are able, to some extent, to evoke (but not to presence) the movements of a dance or the atmosphere of an event, and from the music one can feel things like the mood of the people. Nonetheless, the fact remains that the clean recordings let us experience Indonesian music-and thus picture what it is -in a very different way than when one is present at the musical-but-not-only-musical event.

The technology and the way of experiencing is very much a part of modern Western culture, and one can think of audio recording technology as culturally connected to such "machines" as concert halls (where, like in much music recording, and unlike in most Indonesian contexts, the musical sounds are isolated from the surrounding sounds or "noises"), and generally to our basic assumptions about music and its autonomy. Like photography or museums, recording technology encourages a particular way of experiencing, which the series exemplifies, and both the recording technology and the musicological approach-the focus on the sounds and structures of music-produce the same effect: the separating and lifting of musical sounds from the totality of their world. The danger is that unconsciously, indoctrinated by technology's own mentality (or the mentality of which technology is an expression), we (I) tend to appreciate the clean "hi-fi" sound and think about it as objectively true and good, rather than as something that provides a different experience from what it records.

I remember a cassette that somebody recorded as he was walking around at an Indonesian nightfair, at which different kinds of music (gamelan sekaten, dangdut, pop, and more), as well as many other kinds of human and nonhuman sounds, were mingling. This is not an entirely a-typical sonic event in Indonesia today. If, in presenting the variety of music of Indonesia, the series leaves out certain dominant phenomena such as Western pop and gamelan, then similarly, in recording music uncontaminated by "noise," it leaves out this mingling of different sounds and musics (except when different kinds of music are structurally integrated). Of course, it might be possible to make recordings that would go against the recording conventions, such as the tape just mentioned; or one could, more than it is the case, hear people moving 
or dancing, or the audience talking; and these sounds would evoke the atmosphere, the ambiance. And, if one wanted to make it very authentic and very Indonesian, one might record-to use Yampolsky's own description of one particular instance of a very common phenomenon-the "sound system [as it] blares out the sounds of the singer and the lead [instrument] in a tooth-loosening low-fidelity and renders the other musicians inaudible." (vol. 15, p. 13.) I do not say that this would be a better alternative, and it would be against the concept of the series and the idea of musical recording, but my point is to say exactly that: that technological mediation, like scholarly paradigms, is not neutral. ${ }^{12}$

In some cases, especially when I listen to audio recording of music that is part of theatrical and dance events, I begin to think about the category of music itself. Is the distinction between music and the rest always justified? Between voices and the movements of dancer's bodies and the atmosphere and order of an event? To what extent is the focus on music like selecting a single voice in a symphony, or like focusing on one color in a many-colored picture, or like writing about a mask or a wayang puppet as an art-object lifted out of the context of performance-event? To what extent is the apparent clarity and universality of the distinction a product of "provincial" notions about music, in the same way that Yampolsky shows certain aspects of Western musical terminology to be provincial? In some cases, music seems to stand on its own, and justify the focus on music through its structural wholeness; in other cases, such as when dance movements and visual patterns become integral elements of the formal structure and of the experience, I am not so sure.

This relates not only to the question of how a particular musical event is represented-which aspects and sensations of the event are represented and which are not-but also which kinds of musical events are included in the picture and which are excluded. While there are numerous examples of music accompanying dance, theater, and rituals in the series, the tendency is to focus on music that can be enjoyed by itself, that can stand on its own. On the other hand, music that can be extremely impressive and complex when heard in the context of, for instance, a theatrical performance, but that would lose too much of its power or interest when separated from its context, is generally not included. Th is logical in the context of this kind of audio recording with musicological focus, but this is also another way to understand how the recordings are not neutral or objective ways to represent musical events, but let us perceive only certain things only in certain ways.

In many cases, as I listen to the music, I wish for an audiovisual recording, rather than audio only. Video, when handled creatively and sensitively, can provide a picture of certain aspects of an event and its atmosphere in a way that audio recording cannot. I have recently had a chance to watch an unpublished, unedited video of

\footnotetext{
12 One can think here further about the use of amplification, and modern technology in performance generally, in Indonesia. Usually this is not meant to produce a clean "hi-fi" sound that a musicologist might like, but there is more emphasis on volume, regardless of what we think of as sound quality. One thus hears the technology itself; its power is displayed, rather than concealed. See R. Anderson Sutton, "Interpreting Electronic Sound Technology in the Contemporary Javanese Soundscape," Ethnomusicology 40,2 (Spring/Summer 1996), and Jan Mrázek, "Javanese Wayang Kulit in the Times of Comedy: Clown Scenes, Innovation, and the Performance's Being in the Present World" Part One, Indonesia 68 (October 1999): 7071, 74-75, 112-13, and passim.
} 
gandrung Banyuwangi. I had known the music from volume one of the series, but I have never attended the actual event. Watching the professional female dancers in traditional dress dancing with men in modern clothing, feeling the effortless elegance, energy, sensuality, and humor of the dance movements, and perceiving the social atmosphere of the event, relaxed and excited at the same time, made me again aware of the limits of audio recording specifically in the Indonesian context. But video, just like audio, has its own limitations and provides an experience which is by no means the same as being physically present at an event. As in the case of audio recording, video recording reproduces only certain elements of reality and leaves much out. Thus, one might wish for a series of video recordings that would match the quality of Yampolsky's series, but the videos would not replace the audio recordings, but rather offer a different picture and different experience (part of which still could be cold beer and potato chips).

How does the series relate to other audio recordings of Indonesian music? The editor makes choices on the basis of what recordings of Indonesian music are available in the West and tends to focus on those genres previously not recorded. He often refers to other recordings to complement his picture; or, conversely, he shows how his picture complements the existing recordings. This greatly enhances the picture, and it is also a way of pointing beyond the picture. Incidentally, he does the same with existing literature on Indonesian music. The series is thus an excellent reference work for anybody who needs to know about existing recordings and scholarship.

The series as a whole is clearly different from the thousands of audio-recordings one finds in Indonesian cassette stores. The greatest difference lies in the fact that most of Indonesian recordings are commercial, and this is a decisive factor for the choice and presentation of music. Generally, music that is well-established and/or easily accepted by large numbers of people dominates the market, and regionally popular kinds of music are marketed mostly in the region where the music is well known (where they may affect the music and the local musical scene, positively or negatively). Yampolsky's series focuses precisely on those kinds of music that are little known beyond their localities, and it brings them together into a single whole. Paradoxically, even as the series tries to reveal the little-known, or in part because of that, its audience in Indonesia will be probably very limited. In another sense, this is not paradoxical, because as we have seen, the concept of the series is in opposition to the dominant mainstream forces, one of which is the commercial recording industry. I can imagine the series used at universities and research institutions, and by a few others, but it is unlikely that it will reach broader audiences in Indonesia. But I may be wrong, and it would be interesting to know how the series is faring there. ${ }^{13}$

Yampolsky writes that "much of our work is introductory and exploratory." The series gives a taste of music of Indonesia, whets our appetite, but at the same time always insists that this is only an incomplete selection, that there is much more not published, and there is even more that we do not know ("our recordings are intended

13 For information about the history of the idea of the series, see Perlman's review of vols. 1-12

[Ethnomusicology 42,1: 167-174], mentioned above. 
as stimulating introductions, not definitive expositions." vol. 13, p. 8). In saying "we cannot hope to be complete in twenty volumes," the series points beyond itself to the "tremendous variety" that it "samples"- "[a]s always, then, we must remind the listener that there is more music out there." (vol. 15, p. 11, and elsewhere) It shows persuasively that there is still much work to be done learning about what other people are doing, and it argues forcefully against misleading generalizations by showing what is happening in particular places and with particular people. It thus also argues for the kind of scholarship that it exemplifies: behind the concise commentaries there is impressive erudition-musicological expertise combined with a musician's sensitivity, meticulous study of previous scholarly works, and years of field work-and there is something monumental about the overall design, and about the ability to offer a serious discussion of so many diverse places from all parts of Indonesia. In this age of flashy theory, this kind of scholarship makes one think again, especially because of the liveliness and energy that pervade it. Like a good novel, the commentaries open up our perception of the world and ways of thinking by speaking in detail about what people do. The series presents a vast amount of material to listen to and to think with about Indonesia and about Indonesian music (many of the kinds of music are previously unheard, and often unheard of, outside the places where they are performed), and it presents it in an extremely thought-stimulating manner, raising a variety of important issues. And yet, the series is true to its statement that "what we are producing here is sound recordings, not ethnographic monographs," and even the commentary addresses "the listener," not the reader. It leaves an unlimited amount of work to the listener. This series is obviously extremely significant, yet, rather like a piece of music or a novel, it does not make explicit reflection on its own significance central. It points to further research-indeed opens up a whole new field of research-and further reflection. It makes one wish for more, such as a book about the series that would discuss the many questions and implications lying behind and following after the recordings, but a book that would also give an account of the making of the series-one can catch glimpses of this process in the commentaries-a kind of musical travel-book about the experience of a decade of recording Indonesian music. It makes one also want to know more about other aspects of organizing perception and experience of those people whom one hears. I have talked about the various points that the series makes, and there are many more, some of which are articulated in the recording notes, but ultimately the music is there not as an illustration of a theory, but to listen to and reflect on, and there is always more "out there," not only in Indonesia, but in every piece of music.

I have said in the beginning that Yampolsky should be "applauded" for his work. That's not a bad word for the pompous beginning of a review. But after listening again and again to the music and after rereading the commentaries (and after having to revise this essay again and again), I have a different sentiment, quieter one than "applauding." I feel great respect and admiration for the work. I hope that at least this can be felt from the scattered observations and thoughts that are this essay.

\section{General Discographical information}

The series has been published by Smithsonian Folkways in collaboration with the Indonesian Society for the Performing Arts (MSPI). Each of the twenty volumes contains a compact disc (volumes 1-6 were 
210 Jan Mrázek

published on CDs as well as cassettes) and substantial commentary which includes a general introduction to the series, introduction to the volume, a map, historical, social and cultural background of the musical genres represented, notes on the particular selections, and pointers to further reading and listening (for volumes 1-6 the information is on a folded sheet, for volumes 7-20 it is published in a more convenient 28-page booklet). Illustrations, usually a number of photographs, are on the covers of the booklet and the $\mathrm{CD}$ box. In the case of vocal music, translations of the lyrics are often included. On the Music of Indonesia website, <http://www.si.edu/folkways/Indonesia/indonesia.htm>, can be found transcriptions of original texts, additional translations into English or Indonesian, errata and updates, additional information and references, and a link to a catalogue with sound-samples.

The series has been also published in Indonesia, on both CDs and cassettes. There are two Indonesian editions: one with Indonesian translations of the commentary (checked by Yampolsky) and one with English commentary (incorporating additions and corrections, thus constituting a revised edition of the English commentaries). At the time of writing, only the first ten volumes have been published in Indonesia so far, but the release of the following volumes is said to be imminent. The present review focuses on the American version.

\section{Titles and Discographical Data of the Content of Individual Volumes}

Vol. 1: Songs Before Dawn: Gandrung Banyuwangi. SFW 40055. Recorded 1990, published 1991.

Vol. 2: Indonesian Popular Music: Kroncong, Dangdut \& Langgam Jawa. SFW 40056. Recorded mid70s-1990, published 1991

Vol. 3: Music from the Outskirts of Jakarta: Gambang Kromong. SFW 40057. Recorded 1990, published 1991.

Vol. 4: Music of Nias and North Sumatra: Hoho, Gendang Karo, Gondang Toba. SFW 40420. Recorded 1990-91, published 1992.

Vol. 5: Betawi \& Sundanese Music of the North Coast of Java: Topeng Betawi, Tanjidor, Ajeng. SFW 40421. Recorded 1990 and 1992, published 1994.

Vol. 6: Night Music of West Sumatra: Saluang, Rabab Pariaman, Dendang Pauah. SFW 40422. Recorded 1992, published 1994.

Vol. 7: Music from the Forests of Riau and Mentawai. SFW 40423. Recorded 1993-94, published 1995.

Vol. 8: Vocal and Instrumental Music from East and Central Flores. SFW 40424. Recorded 1993-94, published 1995.

Vol. 9: Vocal Music from Central and West Flores. SFW 40425. Recorded 1993-94, published 1995.

Vol. 10: Music of Biak, Irian Jaya: Wor, Church Songs, Yospan. SFW 40426. Recorded 1993-94, published 1995.

Vol. 11: Melayu Music of Sumatra and the Riau Islands: Zapin, Mak Yong, Mendu, Ronggeng. SFW 40427. Recorded 1993-94, published 1996.

Vol. 12: Gongs and Vocal Music from Sumatra: Talempong, Didong, Kulintang, Salawat Dulang. SFW 40428. Recorded 199-94, published 1996.

Vol. 13: Kalimantan Strings. SFW 40429. Recorded 1995, published 1997.

Vol. 14: Lombok, Kalimantan, Banyumas: Little-Known Forms of Gamelan and Wayang. SF 40441. Recorded in 1996, published 1997.

Vol. 15: South Sulawesi Strings. SFW 40442. Recorded 1996, published 1997.

Vol. 16: Music of the Southeastern Islands: Sumbawa, Sumba, Timor. SFW 40443. Recorded 1997, published 1998.

Vol. 17: Kalimantan: Dayak Ritual and Festival Music. SFW 40444. Recorded 1995-96, Published 1998.

Vol. 18: Sulawesi: Festivals, Funerals, and Work. SFW 40445. Recorded 1996-97, published 1999.

Vol. 19: Maluku: Halmahera, Buru, Kei. SFW 40446. Recorded 1997, published 1999.

Vol. 20: Indonesian Guitars. SFW 40447. Recorded 1990-97, published 1999. 